\title{
Ceres, as mulheres e o sertão. Representações sobre o feminino e a agricultura brasileira na primeira metade do século $\mathrm{XX}^{*}$
}

\author{
Graciela de Souza Oliver* \\ Silvia F. de M. Figueirôa***
}

\begin{abstract}
Resumo
Em quatro escolas superiores de agricultura estudadas o percentual de mulheres no corpo discente ou no corpo docente é estatisticamente desprezível nas décadas de 1930 e 1940. Apesar disso, do ponto de vista dos estudos de gênero e da história das ciências, é importante compreender essa presença para entender e reconhecer o papel das mulheres na sociedade e em particular no meio científico. Nosso propósito não foi o de realizar um balanço aprofundado sobre a carreira seguida pelas engenheiras agrônomas. Outrossim, reunimos o que falavam sobre elas as poesias, os ofícios, algumas fotos e figuras, relacionando essas representações ao processo de institucionalização das ciências agrícolas no Brasil no período.
\end{abstract}

Palavras-chave: História das Ciências Agrícolas, História da Agricultura, Engenheiras Agrônomas.

\footnotetext{
* Recebido para publicação em fevereiro de 2006, aceito em março de 2007.

** Doutora em Ciências pelo Instituto de Geociências, Unicamp. gracioliver@gmail.com

${ }_{* * * * *}^{*}$ História das Ciências, professora titular do Instituto de Geociências/Unicamp. figueiroa@ige.unicamp.br
} 
Ceres, as mulheres e o sertão

Ceres, Women and the Backlands:

Representations of the feminine and Brazilian

Agriculture in the first half of the twentieth century

\begin{abstract}
Our research on the historical trajectory of four Brazilian agricultural schools in the thirties and forties of the twentieth century does not show a significant number of women in the profession. Nevertheless, rethinking these data, inspired by the history of science and gender studies, it is possible to understand the meanings, and the role played of those women within society, and in the scientific milieu. We collected and analyzed speeches, poetry, official documents, images, and photos, which led to a reflection on these representations, as well as the process of institutionalization of agricultural science.
\end{abstract}

Key Words: History of Agricultural Science, History of Agriculture, Women Agronomists. 
Este artigo é resultado de uma pesquisa (Oliver, 2005) $)^{1}$ que buscou compreender se, e como, diferentes projetos políticos de modernização da agricultura, encampados pelas Escolas Superiores de Agricultura, eram amparados por tradições científicas distintas. Além disso, a pesquisa procurou identificar o papel daquelas escolas na institucionalização das ciências agrícolas no país, nas décadas de 1930 e 1940. Nas escolas agrícolas estudadas $^{2}$ notamos que, dependendo de como cada escola se legitimou no campo político, uma proposta de organização para toda a área foi assumida, resultando também em diferentes finalidades para os profissionais formados.

Entretanto, as escolas não se diferenciavam quanto ao paradigma científico adotado, sendo que as estruturas curriculares de todas tinham como eixo as ciências naturais e a engenharia. Os cursos privilegiavam as disciplinas de química orgânica, analítica $e$ agrícola, a produção animal e vegetal $e$, a partir da década de 1920, algumas escolas privilegiaram também a genética. Por outro lado, em função da disponibilidade de profissionais para dar aulas nesses estabelecimentos e de suas relações com outras instituições científicas, cada escola apresentou diferentes canais de institucionalização do saber científico. Em outras palavras, a depender da formação do corpo docente, das suas especializações $e$ interesses científicos específicos, cada escola agregou particularidades a sua estrutura curricular, que lhes conferiram diferenças positivas ou negativas na esfera política local $e$ nacional.

Apesar da diversidade de contextos locais encontramos uma uniformidade - a contraposição entre ser mulher e o exercício da profissão agronômica, que se expressou concretamente no

1 Esta pesquisa recebeu o auxílio da FAPESP sob forma de bolsa de doutorado (00/14946-3).

2 Escola de agricultura da Bahia - 1877/BA - EAB; Escola Superior de Agricultura "Luiz de Queiroz" - 1901/SP - ESALQ; Escola Nacional de Agronomia - 1910/RJ - ENA; Escola Superior de Agricultura de Viçosa 1926/MG - ESAV. 
Ceres, as mulheres e o sertão

número de engenheiras agrônomas que ingressaram na carreira, nas imagens e na esfera do discurso. Assim, este artigo expõe um panorama geral da mulher na sociedade $e$ nas atividades científicas no início do século $\mathrm{XX}$, analisando os quadros de formatura, o perfil de algumas alunas $e$, finalmente, alguns aspectos do processo de emergência das ciências agrícolas no país, a partir da incorporação das mulheres e do feminino na análise.

$\mathrm{Na}$ literatura sobre o ensino superior de agricultura brasileiro quase não há menções sobre o ingresso de mulheres na carreira, desde o período inicial até a década de 1930. A única exceção, a ser confirmada, é Maria Adelaide Pinto Quintanilha, formada em 1919 pela Escola Superior de Agricultura e Medicina Veterinária, que se transformou em Escola Nacional de Agronomia em 1934. Sobre esta agrônoma, o catálogo de ex-alunos daquela escola, de 1960, não traz nenhuma informação sobre a sua inserção profissional, como apresenta para os demais alunos.

$\mathrm{O}$ pequeno ingresso de mulheres nas escolas superiores de agricultura também foi marcante no período posterior a essa data e até 1950. No quadro geral do ensino superior brasileiro, nessa mesma época, outras profissões foram procuradas pelas mulheres - odontologia, farmácia, música e, em um segundo plano bem distante, medicina, direito, pedagogia e economia (Besse, 1999:130). Nos registros do corpo discente da EAB, da ENA e da ESALQ constam apenas 21 mulheres entre os 2090 registros compilados nas pastas de alunos entre 1930 e 1950. Dessas 21 alunas, dez formaram-se na ESALQ, nove na ENA e duas na EAB. A estas podemos somar mais 26 outras mulheres formadas em outras escolas superiores de agricultura na mesma época (Id. ib.).

$\mathrm{Na}$ ESAV, apesar de publicações, clubes e atividades voltadas para as agricultoras, inclusive durante a Semana do Fazendeiro e do Mês Feminino, as primeiras alunas do curso de engenharia agrícola daquela escola formaram-se somente a partir da década de 1950. A primeira foi Maria Elisa Vilela, da turma de 1954, e na seqüência Marly Lopes Tafuri, da turma de 1956, que 
ingressou como docente no departamento de Zootecnia daquela escola no ano seguinte à sua formatura (Borges, Sabioni e Magalhães, 2000:210). Da mesma forma, a filha do professor Alexis Dorofeef $^{3}$, da cadeira de Solos e Adubos - Cláudia de Melo Dorofeef, após sua formatura em 1961 - ingressou como docente no Departamento de Fitopatologia da mesma instituição (Id. ib.:194).

Num livro organizado pelo Conselho Federal de Engenharia, Arquitetura e Agronomia (CONFEA, 1999:35-40), há uma homenagem às "Pioneiras", listando quarenta nomes de mulheres formadas em diversos cursos entre 1917 e 1951, incluindo quatro engenheiras agrônomas. Segundo as estatísticas apresentadas pela pesquisa, os engenheiros agrônomos são a categoria profissional que apresenta, atualmente, a distribuição menos concentrada entre os estados brasileiros, ao contrário de outras áreas profissionais que compõem o Conselho. Todavia, as mulheres sempre foram minoria no curso, preferindo arquitetura $e$ engenharia química, no decorrer do século XX. Entre as pioneiras, os autores identificaram três formadas pela ESALQ, que constam do presente estudo, além de Arlete Veiga Pádua, formada pela Escola Superior de Agricultura de Lavras em 1951 (Id. ib.:47).

Nesse contexto da profissão, predominantemente masculino, o primeiro elemento feminino a aparecer antes de 1930 é a imagem de Ceres nos quadros de formatura, bem como as referências escritas à própria escola como uma figura feminina. Para trabalhar com esses discursos buscamos entender o papel da mulher na sociedade brasileira e na atividade científica, sabendo que interpretações sobre essas imagens e representações auxiliam a compreender o imaginário social da época (Tronca, 1988:277) e a construção de um significado sobre a ciência.

3 Alexis Dorofeef formou-se como engenheiro agrônomo pelo Instituto Agronômico do Estado em Gembloux (Bélgica), como engenheiro agrícola pela mesma instituição e como engenheiro florestal pela Faculdade de Agronomia da Universidade de Belgrado (Iugoslávia). 
Ceres, as mulheres e o sertão

\section{Ceres $e$ as mulheres}

Segundo Londa Schiebinger (1990), a partir do século XIX a representação da ciência como uma figura feminina apresenta-se como uma permanência rara na iconografia científica $e$ distanciada do significado neoplatônico, que lhe atribuía uma realidade superior. Essa imagem deixou de significar a união entre elementos opostos (feminino/masculino, ação/especulação, divino/humano), servindo de guia para homens e, por vezes, para mulheres, até a verdade. A ascensão da filosofia moderna em fins do século XVIII, observa a autora, relacionou as mulheres à maternidade, pondo fim à personificação da ciência e rechaçando as mulheres da atividade científica. Somente a racionalidade masculina, a observação e a experimentação levariam ao conhecimento, resultado também do treinamento científico $e$ não de uma experiência que poderia ser simbolizada de contato com o divino. Assim, o culto à racionalidade e objetividade estiveram vinculados a um movimento de repressão dos sentimentos $e$ da sensualidade e a uma tendência de estabelecer a inferioridade da inteligência feminina (Japiassú, 2001:67).

No período seguinte, com a profissionalização da ciência, as mulheres passaram a encontrar maior dificuldade para pertencer aos círculos científicos ou ingressar nas escolas profissionais. Nesse momento, na iconografia científica, Londa Schiebinger salienta a transformação da figura feminina numa alegoria do divino, ou seja, destituída de um sentido relacionado à prática científica em si. Ao mesmo tempo, tornaram-se freqüentes as fotografias de cientistas sérios e auto-suficientes em seus laboratórios, onde eles são as figuras centrais das ações.

Em contrapartida a esses ideais, a partir da segunda metade do século XIX, as pioneiras do feminismo passaram a questionar a educação feminina. No Brasil, propunham uma educação que possibilitasse a emancipação intelectual das mulheres $e$ a educação adequada das futuras gerações, relacionando essas proposições ao discurso de promoção do progresso ou do ingresso 
do país no rol das nações civilizadas (Besse, 1999:124). Paralelamente, algumas teses foram elaboradas por juristas $e$ médicos apoiando a participação igualitária das mulheres na construção da nova nação brasileira, motivando o voto feminino $e$ - estabelecimento da educação mista nas escolas públicas primárias a partir de 1880 (Id. ib.:125). Tirando essas exceções, outros discursos científicos das Faculdades de Medicina do Rio de Janeiro e da Bahia reforçavam um modelo imaginário de família e de mulher orientado "...para a intimidade do lar, onde devem ser cultivadas as virtudes burguesas" (Rago, 1987:75). Desse modo, ainda que essa preocupação com a educação feminina possibilitasse uma verdadeira "invasão das mulheres no cenário urbano", o papel da mulher não se modificou na sociedade, pois seus conhecimentos serviriam para torná-la uma companhia agradável e interessante ao homem (Id. ib.:62-3). Assim, se desde fins do século XIX algumas delas podiam freqüentar escolas $e$ outros espaços, essa educação visava reforçar e demonstrar a "vocação natural" ou a "missão sagrada" da mulher como "'guardiã do lar".

Da mesma forma que o voto feminino só foi nacionalmente adotado na Constituição de 1934, a educação das mulheres cresceu morosamente, tanto em termos numéricos como qualitativos, conclui Susan Besse (1999:127-8). A autora salienta que, em geral, os cursos secundários eram particulares, mantidos por ordens religiosas e privilegiavam, quando muito, o magistério ou cursos comerciais, excluindo as mulheres de um preparo "científico" para o ingresso no ensino superior, pelo menos, até início da década de 1920.

O caráter científico desses cursos foi sendo introduzido no decorrer da década de 1930 e 1940, visando tornar as mulheres mais preparadas para o papel de reprodutoras dos herdeiros, sempre atentas aos possíveis desvios de conduta moral e sexual, à saúde e à alimentação própria e de seus filhos. Por outro lado, a contínua desigualdade entre homens e mulheres no ensino superior, somada ao crescimento do ingresso de mulheres em 
Ceres, as mulheres e o sertão

cursos secundários profissionalizantes, estabeleceu uma verdadeira divisão social do trabalho, ao invés de uma emancipação intelectual (Id. ib.:142-3). Caberia às mulheres o papel de mantenedoras da ordem social ao invés de transformadoras da realidade, o que se dava fundamentalmente pela manutenção da instituição "família".

Presas à ideologia de que a mulher só era importante quando útil aos outros - à família, ao trabalho ou ambos -, essas profissionais do início do século compreendiam a imposição desse compromisso social como uma forma de liberdade (Passos, 2001:106). Tal contentamento pode ser entendido como uma "estratégia de vida" em meio às tensões ou uma possível desestabilização dos papéis entre os sexos ocorridas naquele momento. O questionamento das referências e padrões culturais, que possibilitavam a construção de identidades sociais e sexuais, se deu tanto pelo impacto das novas técnicas e avanço da industrialização, quanto pela exposição de temas como casamento, amor, divórcio, controle de natalidade, etc. nos variados veículos de comunicação (rádio, livro, jornais, poesias, músicas, piadas, caricaturas, provérbios, etc.) que circulavam, sobretudo, no meio urbano (Moreira, 2002:261, 264). A utilização dessa literatura, paralela ou diretamente relacionada às profissionais da agricultura, permitiu compreender a presença das mulheres na profissão e o que isso nos leva a afirmar sobre o processo de institucionalização das ciências agrícolas.

\section{Representações do feminino da cidade para o campo}

O livro de memórias de Letícia Dultra Brito, filha de Miguel Ferreira Dultra - professor da Escola Politécnica da Bahia e depois da $\mathrm{EAB}$-, aponta para o direito do primogênito em seguir para a Europa, complementando os estudos, enquanto às mulheres cabia apenas o Colégio Alemão, dos oito aos quinze anos, na cidade de Salvador. Depois dessa fase, a educação seria completada em casa com governantas estrangeiras e diversas professoras. Embora 
essa educação não fosse científica, como afirma a autora, "em termos de artes, conhecimentos gerais e línguas, deixavam longe qualquer universitária de hoje!" (Brito, 1997:69).

Em 1900, aos oito anos, Margarida (mãe de Letícia) viajou com a família para a Europa e, acompanhada de governantas, visitou museus, conferências, exposições, concertos, fazendo passeios e compras. Na segunda viagem com a família, em 1910, as governantas levaram-na aos teatros, óperas e bailes. No ano seguinte, casou-se em Salvador, mas enviuvou seis anos depois. Nesse momento da narrativa, a autora enfatiza que Margarida não quis saber de luto, cancelando as roupas negras, pedindo a seu pai para trazer-lhe da Europa roupas de suas cores prediletas e das casas "Jenny", conhecida loja de modas da época. Noivou pelo menos duas vezes antes de conhecer Miguel Dultra num baile de fantoches da Euterpe.

Educado na Europa, seu esposo foi descrito como um baiano culto, embora seus estudos tivessem sido custeados por um tio, pois sua família na Bahia era pobre e numerosa. Fluente em francês, tendo estudado em Portugal no colégio jesuíta de Campolide e Química na Universidade de Lausanne, na Suíça, Miguel agradou a Margarida e casaram-se em 1924. Em seguida, na narrativa, a autora conclui sobre o pai que, devido a uma infância infeliz e carente, Miguel "desenvolveu um gênio pessimista, cético, derrotista de difícil convivência", principalmente em relação à filha do primeiro casamento de Margarida (Id. ib.:154). Apreciadas no meio profissional do qual Miguel fazia parte, essas "qualidades" eram rejeitadas no âmbito da família, conforme a autora fez questão de reproduzir, salientando a vivacidade de sua mãe a despeito das mazelas e sofrimentos por que passara, buscando sempre a preservação de sua beleza, do espírito alegre, dos valores estéticos, da educação dos filhos e da continuidade da família.

É provável que esse papel também tenha sido desempenhado pela mulher de Edmundo Navarro de Andrade, "...por ele apontada como o modelo da companheira em sua vida 
Ceres, as mulheres e o sertão

de agrônomo, no mato" (Domingues, 1941:376, grifos nossos). Esse papel foi referendado como exemplar por Otávio Domingues, professor de Zootecnia na ENA, ao se referir à viúva no obituário daquele agrônomo. Edmundo Navarro de Andrade se formou em 1903 na Escola Nacional de Agricultura de Coimbra, custeado por seu padrinho Eduardo Prado. Ao voltar para o Brasil foi arranjar trabalho, recusando o auxílio de sua tia Veridiana Prado, cuja chácara era um "verdadeiro salão literário, sendo que conhecia $e$ era admirada pelo novelista português Eça de Queiroz" (Love, 1982:124)

Dentro do lar, a companhia feminina podia não ser tão aventureira, conforme observamos nas palavras de Pedro Bloch sobre a esposa de Costa Lima:

No adiantado de sua vida foi conhecer uma criatura excepcional, louvada a uma voz por toda gente: Dona Ana. Ela tinha com ele uma paciência de Jó. Tudo nele passou a ser "Ana, vê isso, vê aquilo; Ana choveu; Ana traz, Ana faz" Tudo (Bloch, 1968:34).

Nesse trecho, a "aventura" ou missão toma a conotação de uma ascensão espiritual por conviver com esse tipo de gênio masculino, como ironiza Pedro Bloch na década de 1960.

A exemplo das personagens de Eça de Queiroz em As cidades $e$ as serras, cuja influência romântica também foi assumida por alguns estudantes da escola baiana (Marques, 1994:114), as mulheres companheiras apresentam semelhanças com Dona Angelina e Ana Vaqueira (Queiroz, s/d:11,191), mas também com Madame de Trèves, que acompanha todos os

...orgulhos da ciência, com astuta candura "...ela sorria, seguia... madame de Trèves não compreendera nenhum aparelho do meu Príncipe! Madame de Trèves não atendera a nenhuma dissertação do meu Príncipe! Naquele gabinete de suntuosa mecânica ela somente se ocupara em 
exercer, com proveito e com perfeição, a arte de agradar (Id. ib.:63).

Nas memórias do engenheiro agrônomo Clibas Vieira temos um pequeno exemplo de como se combinavam os papéis de mulher companheira e de formadora do ambiente doméstico. Ele nos conta sobre como prestava atenção às histórias que sua mãe contava sobre as "aventuras agronômicas do tio Otto" em meados da década de 1930. Isto é, como irmã era companheira no mato, como mãe fomentava inspirações. Segundo José Peres Romero (2001:43), Otto Edmundo Ernesto Behmer formou-se em agronomia na ESALQ em 1905, mas Clibas Vieira sentia um enorme orgulho dele por ostentar o título de engenheiroagrônomo. Para Clibas Vieira, tal titulação era "...mais que um simples agrônomo, de acordo com a minha ingênua crença pueril" (Vieira, 1996:02).

Essa divergência de opiniões no decorrer do tempo, em parte, justifica-se porque na década de 1930 a diferença entre os títulos era motivo de disputa entre a ENA e a ESALQ. Na primeira, estabelecida como padrão em 1934, titulavam-se agrônomos. Na segunda, devido a um decreto estadual de 1925, os agrônomos formados até aquela data poderiam mudar para o diploma de engenheiro agrônomo se cursassem as disciplinas de engenharia. Este deve ter sido o caso do tio de Clibas Vieira, mas não o de outros, como Otávio Domingues, que se formou pela ESALQ em 1917 .

As aventuras eram narradas pela irmã caçula de Otto, que acompanhou o irmão algumas vezes em suas visitas às fazendas em São Paulo. Além do tio e das histórias da mãe, Clibas Vieira também acreditava ter sido influenciado pelo pai no desenvolvimento do "amor" pelas coisas agrícolas, uma vez que ele era funcionário da Secretaria da Agricultura do Estado de São Paulo e trabalhava no Parque da Água Branca, fabricando diferentes tipos de queijo. É interessante notar a metáfora utilizada por Clibas Vieira sobre a origem de sua vocação: 
Ceres, as mulheres e o sertão

"No sítio de meu avô tomei contato com a Natureza e com a Agricultura, o que me plantou no cérebro (ou no coração?) a semente que iria desabrochar alguns anos mais tarde" (Id. ib., grifos nossos).

Nesse trecho, notam-se as características comumente atribuídas ao humano (ativo) e à natureza (passiva), uma relação semelhante àquela que compara o homem à cultura e a mulher à natureza, uma das definições mais comuns que permeiam o conceito de cultura no ocidente (Ortner, 1979:100-101). Ainda nessa citação, as duas sementes: a razão - cérebro (influências paternas, do avô e do tio) e a vontade - coração (influência da mãe) - foram plantadas no engenheiro agrônomo, que as recebe como o solo e espera seu natural desabrochar com o tempo, colhendo, de um lado, a aplicação dos preceitos científicos, de outro, o lirismo do descrever a sociedade.

Entretanto, ao buscarmos o sujeito do verbo plantar, compreendemos que o contato, o sentir, o perceber e o observar a natureza $e$ a agricultura, ações realizadas pelo próprio futuro engenheiro no âmbito da família, "plantaram" ou motivaram a sua vocação. Essa representação de Natureza, incompreensível, obscura, desordenada, e de Agricultura, conhecimento e domínio da natureza para o bem da nação, foi constante nos projetos de modernização agrícola pelo estabelecimento do ensino superior, reforçando o caráter científico das ciências agrícolas, como qualquer outra ciência ${ }^{4}$, ou uma perspectiva da cidade para o campo.

A pretensa inversão das características mais comuns atribuídas aos diferentes gêneros também foi observada por José Eisenberg ao analisar as imagens femininas e republicanas no Brasil (Eisenberg, 1989:23). Em seu artigo, o autor afirma que a

4 Para Japiassú (2001:72-3), a adoção de um projeto machista de ciência acarretou uma transformação do sentido tradicional da natureza, enquanto globalidade, para outra que só pode ser vista pela racionalidade, de forma segmentada, cujas leis devem estar a serviço da civilização humana. 
pátria era vista como mãe soberana e gentil ao prover todas as riquezas necessárias à prole, ao contrário da autoridade firme $e$ inflexível do pai que, de fato, provia o berço com todas aquelas riquezas. Sobre isso, José Eisenberg explica que, no pensamento comteano, no âmbito da família se iniciaria a "evolução das afetividades solidárias", passando da mãe ao pai e à pátria, cuja representação na arte positivista do século XIX se dava pela imagem de Clotilde. Essa relação é feita porque, após um encontro com Clotilde de Vaux, em 1884, Augusto Comte abandonou o racionalismo da sua ciência positiva, transformandoa em uma religião da humanidade, cívica e laica (Id. ib.:30).

Desse modo, compreendemos que as Escolas Superiores de Agricultura seriam mais um local em que os ideais cientificistas dariam continuidade a uma idéia de nação brasileira, desenvolvendo o amor à escola ou à ciência como o amor à nação. Simplificando as matizes dos ideais que envolvem a prática das ciências agrícolas, podemos dizer que personificavam o amor à escola aqueles cujas raízes familiares vinham de algum convívio com a atividade agrícola. Ou, ainda, personificavam o amor à ciência em si aqueles que aprendiam a correlacionar o desenvolvimento da agricultura ao desenvolvimento da nação $e$ que não tinham, necessariamente, convívio com a atividade agrícola. Esses extremos resultaram em representações distintas sobre as escolas, que ao longo da década de 1930 e 1940 foram matizadas e diversificadas.

Para finalizar essa parte, acrescentamos que, além dos costumes, da educação de meninos e meninas, da literatura ficcional e da ideologia que envolvia a institucionalização das ciências agrícolas no país, encontramos durante a pesquisa vários exemplares de livros sobre psicologia em geral. O respaldo fornecido por esse conhecimento compõe mais um elo entre os diferentes contextos regionais nos quais se situavam as Escolas Superiores de Agricultura e destas com a necessidade de tornar a ciência útil à sociedade. Na ENA, em particular, sabe-se que o objetivo da Psicologia era transformar o técnico agrícola em um 
Ceres, as mulheres e o sertão

educador, bem como desenvolver as capacidades potenciais ou inteligências dos alunos, em virtude da forte adesão de alguns de seus professores à eugenia e aos interesses da Sociedade Nacional de Agricultura (Cf. Mendonça, 1998).

Num destes livros encontrado na ESALQ, nota-se uma discussão sobre como deveriam ser as esposas de cientistas (Sanchez e Egidio, 1927). Os autores argumentavam que, sendo quase impossivel encontrar companheiras de pesquisa como Marie Curie (1867-1934), por estarem as mulheres daquele tempo corrompidas pelas "delicias" do consumo, as esposas ideais deveriam ter como características a iniciativa própria e a capacidade de cuidar do lar e da família sozinhas. Essa companheira ideal deveria ser educada para enfrentar qualquer problema cotidiano, porque o esposo estaria ausente na maior parte do tempo preocupado com coisas de "maior enlevo", como experimentos científicos, leituras, congressos, relatórios, publicações e também afazeres burocráticos do mundo da ciência. Nos seus momentos de descanso, confinado em seu escritório, essa esposa jamais poderia requisitar-lhe a atenção.

\section{As imagens de Ceres}

Relacionando o papel proposto à mulher na sociedade brasileira às considerações de Londa Schiebinger, compreendemos que a presença de Ceres nos quadros de formatura pode ser lida igualmente como uma alegoria. Se, no início do século XX no Brasil, as mulheres também eram educadas para a reprodução da família e, ao mesmo tempo, nota-se um processo de profissionalização científica, tanto pelo funcionamento de escolas superiores nacionais como pelo hábito de enviar os primogênitos e sobrinhos para o exterior, um processo em que as mulheres pouco tomaram parte, não é de se estranhar que, nos quadros de formatura analisados, Ceres não apresente a função de guia ou de intermediária entre o homem e a verdade. As imagens que encontramos diferem dos frontispícios dos livros 
científicos do século XVII ao XVIII, cujas figuras femininas eram posicionadas num plano superior e numa perspectiva distante (Schiebinger, 1990:82).

Em nossos materiais, Ceres foi posicionada sempre no plano inferior dos quadros, reafirmando, em parte, a tradição de ser representada como uma musa. Como explica Londa Schiebinger, algumas musas da mitologia Grega foram representadas como figuras abstratas e distantes até meados do século XVIII, mas aparecendo posteriormente também como mulheres reais (Id. ib.:83), por serem de natureza ao mesmo tempo imortal e humana.

Por esse posicionamento nos quadros, as imagens de Ceres podem ser lidas como as de uma musa apenas em sua face humana. Note-se que as imagens exibem um olhar sedutor, mas estão sempre vestidas. Além disso, a imagem foi representada imersa ou próxima da paisagem agrícola, apontando para um lugar, ou para uma inscrição em latim, e dando origem aos novos profissionais. No entanto, na presença ou na ausência da figura feminina, como no caso da ESAV, é possível observar a permanência da hierarquia entre mestres, homenageados $e$ alunos, decorrentes da disposição dessas fotos no quadro. Desse modo, compreendemos que tanto o observador do tempo presente como a "inspiração" compartilham todos os tempos (passado, presente e futuro) na perspectiva e na promessa de uma agricultura moderna.

Como alegoria, sua postura em relação às fotos dos formandos e homenageados pode ser entendida de duas maneiras: como a mulher que semeia ou como a mulher guardiã. Duas atitudes que estão em sintonia ao papel social idealizado para a mulher na época, bem como às duas principais vertentes ideológicas que orientaram a recepção dos conhecimentos agronômicos, atribuindo-lhes algumas finalidades.

A imagem de Ceres como semeadora cria uma dupla ligação para esses profissionais: a ligação com a família agrícola $e$ com a agronomia, ou com o meio científico. Ela os propicia filiação àqueles cuja vocação não vinha pelas raízes rurais, 
Ceres, as mulheres e o sertão

ressaltando a vocação profissional pelo bem da pátria. Isto é claro quando, nessa postura, ela deixa cair sobre a paisagem agrícola suas sementes, gerando seus descendentes - os formandos. Essa ligação também ocorre nas imagens em que Ceres foi representada de forma mais abstrata. Nessas, a descendência também pode ser compreendida quando observamos os prolongamentos da luz que ela emana.

$\mathrm{Na}$ segunda postura, como guardiã, Ceres aparece mais próxima do cenário agrícola do que dos formandos. Segura e mostra os instrumentos agrícolas, plantas e instrumentos científicos, indicando um caminho àqueles para quem a agricultura já fazia parte das suas origens. A sua presença, em particular a do vitral da ESALQ, propõe que a escola seja o lugar do saber científico. Mas note-se que ela tem a postura de guardiã, de quem olha e cuida. Por essa razão, em todos os quadros e nas duas posturas, compreendemos que no momento de passagem $e$ eternizado da formatura, o conhecimento mostra-se internalizado nos formandos, nos instrumentos e na paisagem agrícola.

Por outro lado, com freqüência nota-se a coincidência entre a representação da musa Ceres, a formação de agrônomos no início do século $\mathrm{XX}$, bem como a presença de ramos de café e de fumo. Como se a sua presença garantisse o 'mito de fundação' do conhecimento agronômico e em suas duas principais vertentes, a que detém e a que dispersa conhecimento. Com o tempo, a presença de Ceres tende a desaparecer dos quadros de formatura de engenheiros agrônomos, sendo substituída pelos mesmos objetos científicos que apareciam anteriormente, em conjunto ou separados. Em especial, em meados da década de 1940, há representação da roda dentada nos quadros de formatura, aparecendo sozinha ou próxima ao arado, ou mesmo sendo conduzida por Ceres.

No quadro de formandos da EAB de 1930 entendemos a representação de Ceres como a de uma musa semeando. Mas a homenagem a Gustavo D'Utra e a representação da própria escola - a primeira do país - acima no quadro tornam possível dizermos 
que as duas vertentes que conseguimos identificar com maior facilidade não foram tão homogeneamente disseminadas. Da mesma maneira, na ESAV, que possuía um projeto político semelhante ao da ENA, mas apresentava uma forte ênfase na pesquisa científica, um de seus principais símbolos é uma árvore, além de um brasão bastante peculiar. Tal como a árvore na ESAV, a imagem de Ceres também se tornou um ícone e as duas estão presentes em quase todos os quadros de formatura entre 1940 e 1960.

Na esfera do discurso textual, analisado em amplo conjunto de fontes, as escolas são identificadas como a Casa de Ceres, Templo da Ciência, o lugar onde se aprende os primeiros passos. Enfim, nesses lugares os formandos, como cavalheiros, eram investidos de uma missão civilizatória. Nas sessões solenes de formaturas, a presença ou a invocação de uma figura paterna cumpriria esse papel, por exemplo, como um proeminente mestre, político ou patrono, como o foram Luiz de Queiroz, Gustavo D'Utra, Idelfonso Simões Lopes, Peter Henry Rolfs, Fernando Costa e Landulfo Alves.

$\mathrm{Na}$ formatura da turma de 1952 da Escola Superior de Agricultura de Viçosa, por exemplo, Artur Bernardes foi chamado para ser paraninfo e criticou o fato de ter esperado 25 anos para receber tal convite da escola que ele próprio havia criado. Nesse convite ao ex-presidente Arthur Bernardes, observa-se a relação entre a imagem feminina da escola e a qualidade masculina da ação:

Animados pelo firme pensamento de render em nome da Casa e de cada um de nós, o justo tributo de inteiro reconhecimento à operosidade de V. Excia., a quem cabem os méritos de tão edificante obra que é a Escola Superior de Agricultura da U.R.E.M.G., os FORMANDOS EM ENGENHARIA AGRONÔMICA, por esta Escola, acabam de eleger V. Excia. PARANINFO da turma de EngenheirosAgrônomos de 1952 (...) Inspirados nessas razões, impelidos pelos sentimentos de amor à ESAV, que sempre o admirou, 
Ceres, as mulheres e o sertão

em todos os tempos, esperamos que V. Excia. aceite o nosso convite e participe conosco das alegrias motivadas pelas "Bodas de Prata" desta Escola, e também do jubílio de nossa diplomação, nas solenidades de 15 de dezembro (Vieira, 1996:40).

Desse casamento entre o homem e a ciência, que já durava 25 anos na ESAV, eles aprenderam a honrar a Escola e a internalizar valores como Estudar, Saber, Agir e Vencer. Tais princípios estão ainda hoje gravados nas quatro pilastras de entrada da escola, para além das quais o amor à mulher e futura mãe dos descendentes poderia ser encontrado no footing da praça principal da cidade. Moças nativas e moços da reta, como eram chamados os esavianos, apesar de andarem em sentidos contrários ao redor da praça, encontraram também casamentos duradouros. Sobre estes, até localizamos informações nas páginas da Revista Seiva, uma publicação do centro acadêmico da escola.

\section{Representações sobre as agrônomas $e$ as engenheiras agrônomas}

As escolas superiores de agricultura, lugar das ciências agrícolas, definitivamente, não eram lugares para mulheres, pois estas não poderiam exercer as suas potencialidades naturais. Dessa visão resultaram os versos destinados às agrônomas Clotildes Florença da Costa e Jacy Bondar, formadas em 1937 pela Escola Agrícola da Bahia.

Sobre a primeira escreveu Antonio Marques (1994:135):

Boa e gentil, querida e inteligente, de uma simplicidade sem limite, não há ninguém no mundo que lhe imite esse condão de cativar a gente.

Nela tudo trescala, unicamente, a graça dos espíritos de elite...

$\mathrm{E}$, por certo, não há quem lhe acredite, 
se pelo amor disser que é indiferente.

Só o estudo a fascina, por enquanto.

Só a Agronomia lhe conduz o encanto

De uma vida sem vagos torvelinhos

Clotildes é uma santa, e sem favor, teria a semelhança de uma flor, se a flor mais pura não tivesse espinhos.

Sobre Jacy Bondar, escreveu Floriano Araújo de Mendonça (Id.ib.:137):

Formosa, esbelta, insinuante e viva eis a Jacy - morena flor da Escola.

Todos lhe querem bem, todos cativa seu todo simples de aromal corola. Quem de sua amizade acaso priva se avança mais vai dar "tratos à bola"... Antes da posição definitiva, uma simples "rasteira" o descontrola...

Muito se engana o que estimá-la pensa, se julga já na certa a recompensa...

O que recebe é, bem depressa, o corte!

Jacy gosta de insetos e de tudo que a venha distrair... (até de estudo)! Mas guarda o coração na caixa-forte!

Apesar de terem sido retratadas de acordo com os ideais de mulher, que ainda prevaleciam naquele meio literário sobre o "belo sexo", - o aspecto de santa em uma e o aspecto natural da outra -, foi preciso justificar a presença delas na turma. Como não eram mães, fizeram discretas alusões à sua família, uma vez que não era possível mencionar suas características viris. Filha do Dr. Anísio Justiniano da Costa, Clotildes foi vinculada à elite baiana, $e$ Jacy, por gostar de insetos, é relacionada diretamente à figura paterna de Gregório Bondar, entomólogo russo que chegou a ser professor da ESALQ. Como agrônomas, sua inserção se dá pela 
Ceres, as mulheres e o sertão

família e não pela capacidade de ingressar no projeto de modernização agrícola.

Elas também foram retratadas como mulheres sem vaidades, fazendo notar a simplicidade de uma ou a falta de torvelinhos de outra, ou, ainda, pelo fato de não terem cedido ao cortejo dos colegas de turma, deixando suas potencialidades naturais para depois. Nem mães, tampouco gentis senhoritas, segundo os colegas de turma, Antonio Marques e Floriano Araújo, o que mais importava para elas era a agronomia ou a entomologia, ciências que as encantavam as distraíam, ou seja, estados contemplativos do pensamento - exatamente o contrário do que sugerem os termos técnico e prático tão incentivados no processo de legitimação das escolas. Desse modo, compreendemos que a crítica a Clotildes e a Jacy é mordaz, não somente pelos espinhos e rasteiras, como por terem colocado em dúvida suas capacidades profissionais, enaltecendo o fascínio $e$ não a ação.

Por outro lado, para serem reconhecidas profissionalmente, as qualidades tidas "comumente" como femininas foram afastadas tanto no espaço físico como no espaço simbólico da escrita. Nos relatórios de alunas que pudemos encontrar, as expressões como "encerrando o meu dever de aluna" (grifo nosso), como escreveu Clotildes Florença da Costa em seu relatório de estágio de 1935, não havia menções à grandeza da escola, da agricultura local ou nacional, das pesquisas realizadas, do Estado ou de governantes, ou de algum mestre ou companheiro de profissão. Seja na ENA, ESALQ e EAB, seus relatórios são totalmente descritivos das técnicas observadas e dos conhecimentos envolvidos e, não fosse pelo prenome, não haveria como separar seus relatórios dos da maioria, não abrindo sequer uma pequenina brecha para uma observação pessoal, subjetiva, ou melhor, para duvidar das suas capacidades intelectuais.

Para uma parte dos docentes das escolas agrícolas, as atividades práticas de campo e a linguagem técnica caracterizavam a prática agronômica. Por esse motivo, Otávio 
Domingues tinha dúvidas de que uma mulher pudesse ser uma profissional da área. Consultando a Diretoria do Ensino Agrícola em 1934 recebeu o seguinte ofício:

As condições para a admissão ao primeiro ano da Escola Nacional de Agronomia estabelecem que deverá o candidato submeter-se a um exame vestibular e que a inscrição a esse exame depende da apresentação dos documentos referidos nas alíneas a, b,c,d, do art. 13 do regulamento aprovado pelo dec. 23.857 de fevereiro de 1934. A candidata satisfaz integralmente às exigências das alíneas $\mathrm{a}, \mathrm{b}$, e d mas, quanto ao estabelecido na alínea c mantenho dúvidas quanto à aptidão para os trabalhos de campo, em relação a alguns. É verdade que, na carreira agronômica, poderá uma mulher encontrar vasto campo para o exercício de sua atividade, mas por outro lado encontrará dificuldades inúmeras a vencer (grifo nosso). No regulamento da ENA há restrições para o ingresso no corpo discente e, embora, omisso nessa parte, parece-me, tal como acontece na profissão militar, devam elas se estender ao belo sexo. Diante, porém, da redação do art. 10 do Regulamento e do disposto em relação ao regime de funcionamento da Escola que será o de internato, pareceme deve o assunto ser submetido à autoridade superior (...)

Sobre isso, Otávio Domingues encaminhou à congregação um escrito que foi registrado no mesmo ofício:

Antevejo duas dificuldades ao deferimento puro e simples ao que requer a candidata: 1). No curso de agronomia a prática de campo se me afigura não compatível com a feição física de uma moça. 2). No futuro regime de internato ela constituiria uma exceção dentro do corpo discente. Para atender ao seu requerimento torna-se, pois, necessário contornar as duas dificuldades acima apontadas: I. eximindo-a dos trabalhos de campo e II. fazendo regime de externato. Devemos porém nos prevenir para as alegações precedentes: algum candidato sem físico para aos 
Ceres, as mulheres e o sertão

trabalhos de campo que queira cursar a escola a sombra da concessão acima proposta ou que fora externo por outra exceção qualquer. ${ }^{5}$

As preocupações de Otavio Domingues reforçam sua noção sobre a formação de uma nova classe de homens para a agricultura, que não fossem degenerados, conforme formulava em suas teorias eugênicas (Stefano, 2004:487,492). Esses homens deveriam ter uma capacidade física completa, o principal requisito para a entrada nas escolas e para o exercício da profissão. A entrada de uma mulher abriria um precedente para aceitar um homem menos ativo, ou com algum problema de saúde, para ingressar na função de "desbravador do sertão". As inúmeras dificuldades por que passaria Rita de Cássia, a primeira a requisitar a matrícula na ENA, seriam reais empecilhos desde a sua formação, já que a ela não lhe seria permitido realizar trabalhos de campo, atividade essencial nas Escolas Superiores de Agricultura para complementar e reforçar a aplicabilidade dos conhecimentos teóricos.

\section{O sertão como representação feminina da natureza brasileira}

Estando o sertão em todos os lugares (Lima, 1999:57-62; Arruda, 2000:13-21), os trabalhos de campo nas escolas superiores buscavam antever as dificuldades que os novos profissionais enfretariam ao estabelecer um verdadeiro confronto com as noções misteriosas que ainda existiam na cultura agrícola brasileira. Na ENA, domar essa natureza, no início do século XX, se dava pelas práticas de engenharia mecânica e de manejo do solo. Nas demais escolas, esses trabalhos não se restringiram às

${ }^{5}$ Parecer da Diretoria do Ensino Agrícola do Ministério da Agricultura comentado por Otávio Domingues. Documento encontrado na pasta da aluna Rita de Cássia do ano de 1934, Arquivo Morto da Seção de Protocolo da Universidade Federal Rural do Rio de Janeiro, antiga Escola Nacional de Agronomia. 
disciplinas de engenharia e os formandos eram solicitados a viajar e a andar pela paisagem para reconhecer seus elementos $e$ fenômenos científicos constituintes. Como expressou Antonio Marques (1994:127) “...o agrônomo é, numa definição lapidar, 'o intermediário entre Deus e a natureza, entre a natureza e o homem"".

Intérprete da natureza e da cultura, o agrônomo deveria ganhar respeito junto ao agricultor via conhecimento científico, sem que isso transformasse a paisagem agrícola em urbana. A preservação do sertão ou do campo como uma identidade natural abstrata, global e desconhecida permitia que as escolas segmentassem essa noção através do conhecimento científico, instituíssem eventos específicos para esse lugar, como as Semanas dos Fazendeiros, Semanas do Milho, Exposições Agrícolas, Dia da Árvore, etc. reafirmando assim, uma atuação profissional exclusivamente masculina. Da mesma forma que o trabalho de medição e mapeamento, as ciências agrícolas definiram o tipo de agricultura para esse solo, iniciando um processo de destruição simbólica de "um horizonte espacial coletivo" (Arruda, 2000:21).

Definida a cidade em contraposição ao sertão, em que eram ressaltadas as diferenças entre o papel dos homens e das mulheres na sociedade, não caberia às mulheres da cidade a luta de civilizar e domar a natureza. Por outro lado, o ambiente urbano em que as escolas da Bahia e do Rio de Janeiro estiveram situadas inicialmente ou com o qual mantinham estreitas relações, como é o caso da ESALQ, o ingresso de mulheres pode ter sido incentivado pelo exemplo de outras mulheres na busca por uma carreira profissional, bem como pelo pouco prestígio que desfrutava a agronomia entre as engenharias, sendo seu caráter de ensino superior sempre contestado em relação aos demais cursos. Às mulheres desse sertão caberia uma educação particular, como ocorreu em Minas Gerais, dando ao trabalho agrícola feminino o suporte científico da nutrição, da economia e da higiene. Dessa maneira, às mulheres que ingressaram nesse ramo do ensino superior cabia estar próximas à natureza, como 
Ceres, as mulheres e o sertão

agricultoras e regentes da família ou como observadoras, nunca como implementadoras da nova natureza racional e científica do campo agrícola.

Mas assim, de onde podiam adotar outros padrões culturais e identitários se, segundo Jeni Vaitsman (1994:91-2), somente a partir da década de 1960 teria havido o aumento do número de vagas e o incentivo por parte dos pais ao estudo científico? Havia exemplos de mulheres trabalhando, mas como se solidarizar $e$ encontrar os caminhos numa carreira permeada por discursos $e$ gestos masculinos?

A exemplo de Jacy Bondar, encontramos na ENA Theonila de Novaes, Maria do Carmo da Costa Monteiro e Dirce Pinto Pacca, filhas, respectivamente, de Benvindo de Novais, formado pela ESAMV em 1919, de Honório da Costa Monteiro, Catedrático de Botânica da ENA e de João Pinto Pacca, agrônomo fitopatologista do Instituto Biológico de Defesa Sanitária do Rio de Janeiro. A segunda entrou para o corpo docente da ENA como professora assistente em 1949. Na mesma condição social, na ESALQ, encontramos apenas Cândida Helena Teixeira Mendes que era filha de Carlos Teixeira Mendes, formado pela ESALQ em 1908. Assim, o convívio familiar que tanto motivou os filhos de agricultores e professores de agronomia teria motivado também suas filhas.

De um total de dez alunas formadas no período, além de Cândida, quatro outras alunas - Yone Guimarães Penteado de Castro, Odette Zardetto de Toledo, Antonieta Pigatti e Veridiana Victória Rossetti - tinham irmãos formados ou que iriam se formar na ESALQ. Além destas, Maria Regina de Almeida Souza, formada em 1948, tinha um irmão formado pela ESAV em 1943, sendo ambos filhos de um agricultor na Bahia. Essa característica, ou o fato de mais da metade das alunas ter irmãos na mesma profissão, acompanha uma particularidade da composição geral do corpo discente daquela escola. Do total de registros analisados na ESALQ (885), 166 alunos apresentavam um parentesco de primeiro grau (irmão ou irmã) com outro aluno $(18,8 \%)$, enquanto que nas 
demais escolas os percentuais eram menores: $\operatorname{ESAV~(7,7\% ),~EAB~}$ $(9,1 \%)$ e ENA $(4 \%)$.

Outra brecha para a inserção de mulheres na profissão parece ter acontecido em relação à origem das alunas na ENA, sendo que das nove formadas, três ingressaram na década de 1930 (1934, 1936, 1939) e nasceram no estado do Rio de Janeiro (duas no Distrito Federal e uma em Sta. Maria Madalena). Na década de 1940, apenas uma era nascida no Distrito Federal, enquanto as demais nasceram em Vitória (ES), Olinda (PE), São Luiz (MA), Belo Horizonte (MG) e Bauru (SP). Na ESALQ, apenas três também ingressaram na década de 1930 (1936, 1938 e 1939), sendo todas paulistas, mas nascidas em cidades diferentes: Palmeiras, Piracicaba e Monte Alto. Das cinco restantes, todas ingressaram na década de 1940, três nasceram em Piracicaba, uma em Salvador e outra em São Paulo. Esse padrão de distribuição geográfica das alunas corresponde perfeitamente ao padrão observado no conjunto geral das turmas nas duas principais escolas. Essa pertinência possibilita especularmos sobre a dimensão da propaganda das escolas, bem como sobre um provável contato dessas alunas com estudantes das escolas em sua terra natal ou entre os familiares.

Em relação ao ensino secundário também encontramos convergência no conjunto de dados analisados. Notamos que as escolas secundárias das alunas são as que mais se apresentam entre os registros, reforçando a idéia de que as Escolas Superiores de Agricultura terminaram formando uma clientela, constituída de locais preferenciais de acesso de acordo com o curso secundário. Contudo, entre as mulheres, nenhuma escola em particular parecer ter funcionado como um canal preferencial de acesso ao ensino superior. Na ESALQ, quatro alunas estudaram na Escola Normal Oficial de Piracicaba, duas no Ginásio Piracicabano, duas no Externato São José de Piracicaba, uma no Colégio Estadual de Piracicaba e outra no Colégio Estadual de Campinas, a despeito das localidades em que nasceram. Na ENA encontramos apenas seis registros sobre a escola secundária e, embora a grande parte 
Ceres, as mulheres e o sertão

dessas escolas estivesse situada na capital, não se nota nenhum canal preferencial de acesso ao ensino superior ${ }^{6}$. $\mathrm{Na}$ EAB não encontramos esse dado sobre as duas alunas, mas localizamos a requisição de matrícula de Neomésia Theodolinda da Costa, irmã de Clodildes, cujo pedido foi indeferido por ter apresentado baixas notas no curso secundário.

Para o professor catedrático de Agricultura Geral da ENA, Arthur Eugênio Magarinos Torres Filho, a escolha das profissões no país dava-se mantendo a ocupação dos pais, ou seja, privando o despertar da verdadeira vocação. Contudo, contraditoriamente, ele criticava o não seguimento da profissão agrícola entre filhos de agricultores:

A Agricultura foi, entre nós, a mais nobre das profissões. É verdade que nela se conservam ainda as mais resistentes ligações da família brasileira. O café e a cana-de-açúcar poderiam ser consideradas as plantas sagradas do Brasil.

Foi a cana que civilizou o norte e o café que enriqueceu o sul. Mas os jovens que cresceram à sua sombra em vez de se prepararem para a lavoura nas escolas agrícolas, vão buscar um pergaminho de doutor nas faculdades (Tobias Monteiro apud Torres Filho, 1942:208; grifos no original).

A identificação dessa recusa, principalmente para dois agrônomos formados pela ESALQ, Torres Filho (1910, nascido em Campos/RJ) e Otávio Domingues (Acre, 1917), aparece como uma grande frustração, motivando-os a defender que o ensino agrícola fosse iniciado o mais cedo possível, para que a nação não perdesse essas aptidões originadas na família. As mulheres que tinham contato com a profissão ou com o ambiente rural não escaparam a essa ideologia.

\footnotetext{
${ }^{6}$ São elas: Nossa Senhora de Sion, Ginásio 28 de Setembro, Colégio Cardeal Leme, Colégio da Universidade do Brasil, Colégio Anglo Americano e Colégio Estadual do Espírito Santo
} 
A mesma opinião é partilhada pelo professor de psicologia e sociologia da ENA em 1942, quando a Segunda Guerra Mundial veio reforçar o papel da agricultura e da educação agrícola na prosperidade da nação:

E essa campanha titânica compete aos agrônomos. Mas só os autênticos profissionais, de vocação, de naturais aptidões podem ter essa dedicação sem limites, que faz os missionários e apóstolos nas horas decisivas da Pátria. É preciso pois encontrar os homens da agronomia nas gerações novas que surgem para a redenção da Nação do cativeiro da rotina (Veiga, 1942:61).

Todavia, dada essa vinculação entre o profissional, o campo e a política agrícola, coube às mulheres lugar de "menor" destaque, o que não se revela pelo lugar em que desenvolveram suas carreiras, mas pelo tipo de atividade. Assim, nessa brecha, à exceção de Laís Piedade e Lídia Nobrega de Lemos - cujos primeiros trabalhos profissionais se deram, respectivamente, na Coletoria Federal do Estado de São Paulo e na Diretoria do Ensino Agrícola, na Superintendência do Ensino Agrícola e de Medicina Veterinária -, Norma Bergalo de Arruda e Dirce Pinto Pacca de Souza Brito ingressaram no Instituto de Ecologia e Experimentação Agrícola, situado desde 1938 no $\mathrm{km} 47 \mathrm{da}$ rodovia Rio-São Paulo; Dinah Mochel de Menezes e Rita de Cássia Rangel Azevedo de Lacerda na Defesa Sanitária do Estado da Guanabara, segundo o catálogo de ex-alunos do centro acadêmico da ENA da década de 1960. Na mesma orientação profissional seguiram Jacy Bondar e Clotildes da Costa, tendo sido encaminhadas, assim como os outros alunos, pelo Diretor da Escola, a fazerem um estágio, respectivamente, no Instituto do Cacau em Ilhéus e na Estação Experimental de Alagoinhas sobre citricultura.

Das formadas pela ESALQ, pudemos apenas recolher alguns dados sobre Odette Zardeto, Veridiana Victoria Rosseti, Alice Cossa, Antonieta Pigatti, Yone Penteado e Maria de Lourdes 
Ceres, as mulheres e o sertão

Canto. A primeira desenvolveu sua carreira no Instituto Agronômico de Campinas na área de vitivinicultura; Victoria Rosseti ingressou no Instituto Biológico de São Paulo, desenvolvendo importantes trabalhos sobre a tristeza do citrus e também trabalhou na identificação do vírus, possibilitando à Estação Experimental de Citricultura de Limeira a distribuição de mudas resistentes à doença (Costa, 1984:47-48 e Ramos Filho, 1999), aposentando-se na década de oitenta como pesquisadora nível 1A do CNPq. Antonieta Pigatti também ingressou no Instituto Biológico, aposentando-se como pesquisadora científica nível VI na mesma instituição. Na Secretaria de Agricultura do Estado de São Paulo, Yone Penteado ingressou no Posto de Fiscalização Sanitária e Maria de Lourdes como engenheira agrônoma mensalista, mas ambas não desenvolveram carreira na Secretaria. Alice Cossa ingressou na Coordenadoria de Assistência Técnica Integral (CATI) de São Paulo e se aposentou como supervisora do Posto de Sementes no mesmo órgão.

Analisando esses exemplos, sem contar com as alunas formadas pela $\mathrm{EAB}$, das quais não obtivemos dados, notamos que, das 21 formadas, nove desenvolveram carreiras voltadas para a experimentação, cinco na área de fitopatologia. O ingresso de mulheres em áreas cujas práticas se davam dentro do laboratório pode ser entendido como uma contradição, se levarmos em conta as proposições de Londa Schiebinger apresentadas no início do artigo. Mas está em total acordo se compreendemos o lugar da mulher na sociedade brasileira e a construção das Ciências Agrícolas no país. A dificuldade de legitimação profissional das mulheres em determinadas áreas ou atividades que pressupunham uma intervenção com instrumentos (outras materialidades) no campo era a mesma das áreas subsidiárias, como a zoologia e a botânica. Sem querer diminuir o enfrentamento das mulheres a 
esses obstáculos, é importante trazer à tona as estruturas gerais de ordenamento do campo e como as mulheres se engajaram nele. ${ }^{7}$

A lógica que as impedia, e que permeou a institucionalização das ciências agrícolas, era a mesma que permitia a sua entrada, ou seja, a necessidade extrema de receber, adaptar, criar e disseminar um conhecimento útil. Essa utilidade/ finalidade das ciências agrícolas foi constituída referendando um discurso sobre a ação no campo, no reconhecimento científico da paisagem agrícola, para o emprego de novos instrumentos e no aprendizado da engenharia. A presença dessas orientações fez com que as escolas superiores de agricultura fossem aos poucos igualadas em prestígio aos demais cursos superiores do país. Nesse sentido, não foi o estabelecimento de uma cultura científica do laboratório, do microscópio e da biologia em geral que legitimou as ciências agrícolas na sociedade brasileira. Essas novas referências paradigmáticas, incorporadas a partir da década de 1940, permitiram que as mulheres já inseridas constituíssem longas carreiras nas décadas seguintes. De uma presença feminina simbólica e mesmo difusa, começamos a notar uma presença constante e crescente nesse campo profissional e disciplinar.

Nesse caso, apesar de pequena, contingente e orientada para uma dada atuação, a participação dessas primeiras mulheres no campo das ciências agrícolas foi efetiva e abriu um viés profissional que se estende até os dias de hoje. Em um balanço sobre as carreiras científicas levadas adiante pelas mulheres em 1999, chama a atenção a maior proporção de mulheres, em relação aos homens, fazendo mestrado strito sensu em várias áreas do conhecimento, em ordem decrescente: Ciências Biológicas, Lingüística, Letras e Artes, Ciências Humanas, mas também Ciências Agrícolas, apesar desta área ainda não se

\footnotetext{
7 Apesar de não termos nos debruçado sobre as trajetórias e documentação escrita pelas próprias engenheiras agrônomas, este artigo busca dialogar com a necessidade de se compreender como se deu a interconexão entre raça, gênero e ideologias colonialistas nas ciências, tal como salientou Lopes (1998:366).
} 
Ceres, as mulheres e o sertão

destacar entre as profissões mais procuradas pelas mulheres (Rosenberg, 2002:172).

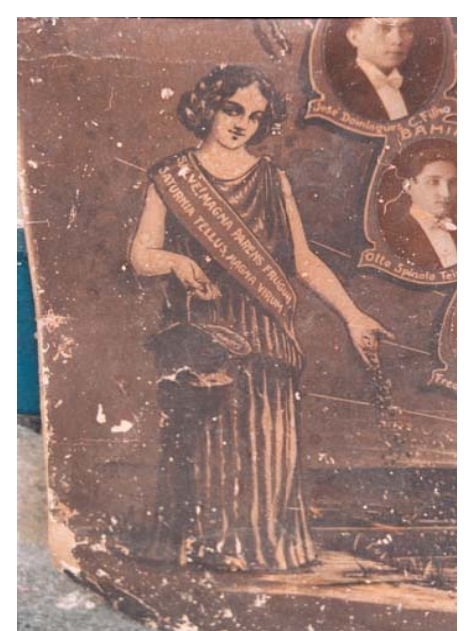

Detalhe do Quadro de formatura da EAB de 1930

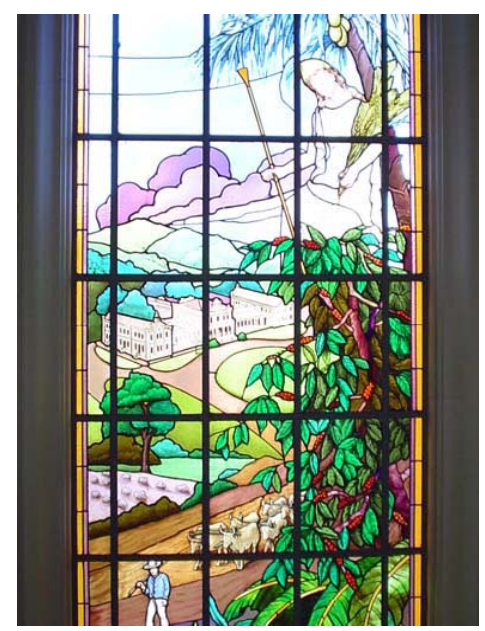

Vitral da ESALQ - prédio Central

\section{Referências bibliográficas}

ARRUDA, Gilmar. Cidades e sertões: entre a história e a memória. BauruSP, EDUSC, 2000.

BESSE, Susan K. Modernizando a Desigualdade: Reestruturação da Ideologia de Gênero no Brasil, 1914-1940. São Paulo, EDUSP, 1999.

BLOCH, Pedro. Vida e Obra de Costa Lima. Col. Vultos da Ciência 1. Rio de Janeiro, CNPq, 1968.

Borges, J. M., SABioni, G. S. e MAgalhães, G. F. P. (eds.) A Universidade Federal de Viçosa no século XX. Viçosa-MG, UFV/ Impr. Univ., 2000.

BRITO, Letícia D. No tempo de minha mãe, Salvador - Bahia. Salvador, Casa de Cerimonial e Museu/Fundação Cultural do Estado da Bahia, 1997. 
CONFEA. As mulheres da Área Tecnológica da Engenharia, arquitetura e agronomia no Brasil. Uma pesquisa quantitativa e comparativa entre homens e mulheres na área tecnológica da engenharia, arquitetura, agronomia, geologia, meteorologia e geografia. Brasília, Graf. Ed. GS4, 1999.

Costa, A. S. 50 anos de fitovirologia. In: O Biológico, Biológico, 50 (Supl. Cong. Fitopatol.), São Paulo, 1984, pp. 45-52.

Domingues, Otávio. Obituário de Edmundo Navarro de Andrade. Boletim da Sociedade Brasileira de Agronomia, dezembro de 1941.

EISENBERG, José. Patriotismo e gênero na tradição do pensamento político moderno: uma genealogia, Revista USP, $\mathrm{n}^{\circ} 1$, março-maio, 1989, pp.22-35.

JAPIASSÚ, Hilton. O projeto masculino-machista da ciência moderna. In: SoARES, L. C. (org.) Da Revolução Científica à Big Science. São Paulo, Hucitec/EDUFF, 2001, pp.67-104.

LIMA, Nísia Trindade. Um sertão chamado Brasil: intelectuais e representação geográfica da identidade nacional. Rio de Janeiro, Revan, IUPERJ/UCAM, 1999.

LOPES. Maria Margaret. Aventureiras nas ciências. Refletindo sobre Gênero e História das Ciências Naturais no Brasil. cadernos pagu (10), Núcleo de Estudos de Gênero - Pagu/Unicamp, 1998, pp.345368.

LOVE, Joseph. A locomotiva. São Paulo na Federação Brasileira, 18891930. Rio de Janeiro, Paz e Terra, 1982.

MARQUES, Antonio Nonato. A Poesia era uma festa. Salvador, GRAPH Co Editora, 1994.

MEndonçA, Sonia Regina. Agronomia e Poder no Brasil. Rio de Janeiro, Vício de Leitura, 1998.

MOREIRA, Maria de Fátima Salum. Mulher, Casamento e Amor: Reordenamentos Sociais nas décadas iniciais do Século XX. In: SAMARA, E. M. Historiografia Brasileira em Debate: "olhares, recortes e tendências". São Paulo, Humanitas/FFLCH/USP, 2002, pp.259286.

OLIVER, Graciela de S. O papel das escolas superiores de agricultura na institucionalização das ciências agrícolas, 1930 e 1950: práticas 
Ceres, as mulheres e o sertão

acadêmicas, currículos e formação profissional. Tese de Doutorado, IG/UNICAMP, Campinas, 2005.

ORTNER, Sherry B. Está a mulher para o Homem assim como a natureza para a cultura. In: ZIMBALIST, M.; LAMPHERE, R. L (coords.) A mulher, a cultura e a sociedade. Rio de Janeiro, Paz e Terra, 1979, pp.95120.

PASSOS, Elizete. Entre a autoridade e o afeto: Anfrísia Santiago e a Educação Feminina na Bahia. In: SARDENBERG et alli (orgs). Fazendo Gênero na Historiografia Baiana. Salvador, NEIM/UFBA, 2001, pp.105-118.

QUEIROZ, Eça de. As cidades e as serras. Rio de Janeiro, Edições de Ouro, $n^{\circ} 477, \mathrm{~s} / \mathrm{d}$.

RAMOS FILHO, Luiz Octavio. O papel da pesquisa cientifica e tecnológica no desenvolvimento da citricultura paulista: analise histórica da atuação do Instituto Agronômico de Campinas (1920-1960). Dissertação de mestrado do DPCT/IG/UNICAMP, Campinas, 1999.

ROMERO, José P. ESALQ Centenária. Escola Superior de Agricultura "Luiz de Queiroz", notáveis, docentes e filhos nobres. São Paulo, Ceres, 2001.

Rosenberg, Fúlvia. Políticas educacionais e gênero: um balanço dos anos 1990. cadernos pagu (16), Núcleo de Estudos de Gênero Pagu/Unicamp, 2002, pp. 151-198.

SAnCheZ, J. R. e EgIDIO. V. F. Psicologia General. Madrid, Hernando, 1927.

SCHIEBINGER, Londa. Cuando la Ciencia era mujer. In: ORDÓNEZ, Javier e ElENA, Alberto. (comps.) La ciencia y su público: perspectivas históricas. Estudios sobre la ciencia, $\mathrm{n}^{\circ} 12$, Madrid, Consejo Superior de Investigaciones Científicas, 1990, pp.71-111.

STEFANO, Waldir. Relações entre a eugenia e a genética mendeliana no Brasil: Otávio Domingues. In: Martins, R. A., Martins, L. A. C., Silva, C. C., FerReIRA, J. M. H. (eds.) Anais do terceiro encontro de filosofia e história da ciência no Cone Sul. Campinas, AFHIC, 2004, pp.486-495.

TORRES FILHO. Aptidões profissionais. Agronomia, vol. 4, agosto-outubro, 1942. 
TRONCA, Ítalo Arnaldo. A questão do Imaginário na prática do Historiador. In: D'AmBROSIO, Ubiratan. (org.) Anais do segundo Congresso latino Americano de História da Ciência e da tecnologia. São Paulo, Nova Estella, 1988, pp.275-277.

VAITSMAN, Jeni. Flexíveis e Plurais. Identidade, casamento e família em circunstâncias pós-moderna. Rio de Janeiro, Rocco, 1994.

VeIGA, Augusto César. As novas diretrizes profissionais e o eterno sonho da abastança popular. Agronomia, vol. 1(2), fevereiro-abril, 1942.

VIEIRA, Clibas. O feijão e eu: memórias de um ex-aluno da ESAV. Viçosa-MG, Imprensa Universitária, 1996. 